\title{
Use of Ozone-Based Eye Drops: A Series of Cases in Veterinary and Human Spontaneous Ocular Pathologies
}

\author{
Leopoldo Spadea $^{\mathrm{a}} \quad$ Emanuele Tonti $^{\mathrm{a}} \quad$ Andrea Spaterna $^{\mathrm{b}}$ \\ Andrea Marchegiani ${ }^{b}$ \\ aDepartment of Medico-Surgical Sciences and Biotechnologies, Sapienza University of \\ Rome, Rome, Italy; ${ }^{b}$ Veterinary Teaching Hospital, School of Biosciences and Veterinary \\ Medicine, University of Camerino, Camerino, Italy
}

\section{Keywords}

Antimicrobial agents $\cdot$ Corneal ulcer $\cdot$ Keratoconjunctivitis $\cdot$ Ozone

\begin{abstract}
Conjunctivitis, keratoconjunctivitis, and corneal ulcers are common eye disorders frequently diagnosed in both humans and animals, and are currently treated by topical administration of eye drops containing anti-inflammatory and antibacterial agents. The current molecules often lack efficacy because infections in hypoxic tissue contain methicillin-resistant Staphylococcus aureus and Pseudomonas aeruginosa; thus, new products for the treatment of ocular pain and inflammation are needed. The use of ozone, a molecule stabilized for topical use as an ozonide, could be providential due to its anti-inflammatory and bactericidal activity in certain anterior segment pathologies, in addition to promoting tissue repair properties. Ozonated oils have the same properties as gaseous ozone and are well tolerated by tissues. In the present study the repair and regeneration effect of ozonated oil in liposomes plus hypromellose (Ozodrop ${ }^{\circledR}$, FB Vision, Ascoli Piceno, Italy) instilled 3-4 times a day in external ocular spontaneous pathologies both in animals and humans are reported.




\section{Case Reports in Ophthalmology}

\section{Introduction}

Ozone $\left(\mathrm{O}_{3}\right)$ gas is a molecule consisting of three atoms of oxygen in a dynamically unstable structure due to the presence of mesomeric states [1]. Thanks to its great oxidative power, ozone has been widely recognized as one of the best bactericidal, antiviral, and antifungal agents [2].

In spite of its oxidative effect, an adequate ozone dose can trigger several useful biochemical mechanisms and reactivate the antioxidant system (i.e., catalase, superoxide dismutase, glutathione peroxidase, etc.) [3]. Furthermore, ozone has been used as a clinical therapeutic agent for chronic wounds, such as trophic ulcers, ischemic ulcers, and diabetic wounds. The beneficial effects of ozone on wound healing might be assumed to be due to the upregulation of platelet-derived growth factor, transforming growth factor- $\beta$, and vascular endothelial growth factor expressions, the decreased bacterial infection, ameliorated impaired dermal wound healing, or increased oxygen tension by ozone exposure in the wound area [2]. Ozone in the gaseous state is extremely reactive and not always suitable as a topical treatment. In saline solution, its concentration reduces quickly with a first-order kinetic and its half-life is 2 $\mathrm{h}$ : this means that in about $24 \mathrm{~h}$ very little ozone will be left in the solution. Interestingly, in spite of its instability, the ozone molecule can be stabilized - for topical use - as an ozonide between the double bonds of a monounsaturated fatty acid such as oleic acid [4, 5]. Ozonated oil is now used topically for the treatment of wounds, anaerobic infections, herpetic infections (HSV I and II), trophic ulcers and burns, cellulitis, abscesses, anal fissures, decubitus ulcers (bed sores), fistulae, fungal diseases, furunculosis, gingivitis, and vulvovaginitis [6].

The use of ozone in certain eye anterior segment pathologies could be providential due to its anti-inflammatory and bactericidal activity, in addition to promoting tissue repair properties. Unfortunately, ozonated oil is highly irritant for corneal tissue; thus, a specific formulation has been recently developed for ophthalmic use, based on liposomal sunflower ozonated oil plus hypromellose (Ozodrop ${ }^{\circledR}$, FB Vision, Ascoli Piceno, Italy), which is extremely biocompatible with the delicate ocular surface tissue.

In our experience, this new liposomal ozonated oil formulation, specifically intended for ophthalmic use, was used to promote wound healing and treat some infective pathologies in common eye disorders encountered in both humans and animals. Inflammatory anterior segment diseases necessitating adequate anti-inflammatory therapy, such as conjunctivitis, keratitis, keratoconjunctivitis sicca, and corneal ulcers, are the most common eye disorders encountered in animals [7] and share some symptoms with humans, such as redness, chemosis, and exudation.

A topical dosage of one or two drops of collyrium every 4 h over 3-7 days is recommended, even though multiple and frequent instillations are often required to achieve clinical resolution, and some patients tend to become noncompliant with frequent medications $[7,8]$. The current agents are quite expensive and they often lack efficacy because infections in hypoxic tissue contain methicillin-resistant Staphylococcus aureus and Pseudomonas aeruginosa; in some cases, they are inadequate and can cause unacceptable side effects.

In particular, there is a need for new products for the treatment of ocular pain and inflammation, such as during external ocular infections and inflammations, due to the related risk of blindness. The overuse of antibiotics in the treatment of infectious diseases, and the appearance of multidrug-resistant bacterial strains, has driven research towards the study of antimicrobial agents from essential oils [9]. Ozonated oils have the same properties of gaseous ozone, are well tolerated by biological tissues (corneal tolerability is increased in a liposomal formulation), and their biological activities are related to oxygenated compounds [9]. They 
are able to eliminate the pathogens by direct oxidation mediated by hydrogen peroxide, lipoperoxyde, and selective cytotoxicity on fast-dividing cells. This occurs through bacterial lysis and cell death, negative regulation on mitochondrial activity in bacteria, and disturbance of viral lithic enzymes, in superimposable manners compared to those of phagocytic cells of the immune system [10]. Moreover, ozone allows a "physiological" wound healing, minimizing the risk of keloidal scar and also the risk of haze in the cornea.

In addition, ozone promotes cell adaptation to oxidative stress and attenuates pathophysiological events mediated by reactive oxygen species. Ozone oxidative preconditioning significantly decreased malondialdehyde levels and increased the activity of superoxide dismutase, glutathione peroxidase, and catalase. Serum interleukin- $1 \beta$ levels tend to decrease with ozone oxidative preconditioning [10]. Based on the many features and possible applications of ozone, the aim of the present study was a preliminary evaluation of repair and regeneration effect of ozonated oil in liposomes plus hypromellose (Ozodrop ${ }^{\circledR}$ ) instilled 3-4 times a day in external ocular spontaneous pathologies in both animals and humans.

\section{Veterinary Case Reports}

\section{Case 1}

A 26-year-old, neutered male, Italian saddle horse, was referred to the Veterinary Teaching Hospital of the University of Camerino because of right eye exophthalmos due to retrobulbar neoformation (probably neoplasm/osteosarcoma) and recurrent conjunctivitis, which had been treated with topical antibiotic (tobramycin) and both topical and systemic NSAIDs (piroxicam plus flunixine meglumine) without any significant improvement. On the day of presentation the horse showed a normal left eye; regarding the right eye, the symptoms were blepharitis and blepharospasmus, edematous and hyperemic conjunctiva, and plenty of mucous ocular discharge (Fig. 1). The day after the beginning of the therapy, blepharospasmus disappeared, and a reduction in blepharitis and conjunctival edema was noted. Moreover, there was a slight reduction in ocular discharge. After 3 days of therapy blepharitis and conjunctivitis disappeared and after a week of therapy the eye became completely normal (Fig. 2)

\section{Case 2}

A 6-month-old male European short hair cat (Fig. 3) was affected by chronic conjunctivitis present from birth, which was unresponsive to the traditional antimicrobial and anti-inflammatory therapy. The day of presentation the cat showed marked conjunctival edema, especially in the right eye, reddening of the conjunctiva, and mucous discharge in both eyes. Conjunctival bacteriological swabs revealed normal bacteria count in the right eye (20 CFU) and the presence of Staphylococcus spp. and Enterococcus spp.; an increased amount of Staphylococcus spp. (140 CFU) in the left eye was detected. Therapy was consistent with instillation of one eye drop of collyrium in both eyes, twice a day until clinical and bacteriological resolution. After 3 days of therapy the conjunctival bacterial count became normal in both eyes (20 CFU) and Enterococcus spp. disappeared. After 10 days of therapy the conjunctival symptoms were no longer detectable (Fig. 4).

Case 3

A 3-year-old male English bulldog (Fig. 5) was referred to our department because of the presence of chronic keratitis in the right eye due to entropion of both eyelids. Because of other 
problems not related to the presenting pathologies, it was not possible to operate on the dog immediately due to the high risk of general anesthesia and, in accordance with the owner, it was decided to begin topical therapy with instillation of one drop of collyrium twice a day until surgery. On the day of the presentation the dog showed keratitis, corneal edema, and deep and superficial neovascularization. Discomfort, pruritus, and ocular mucous discharge were also present. After 10 days of therapy, keratitis had almost disappeared, corneal edema was resolved, and neovascularization remained only with a single, small caliper vessel arising from the limbus at the level of the medial cantus (Fig. 6). Entropion and mucous discharge were still present.

\section{Human Case Reports}

Case 1

A 33-year-old man with a history of improper use of contact lens, including continuous wear, presented himself at our department with left eye pain, redness, and photophobia for 2 days. Correct distance visual acuity was $20 / 25$. Slit-lamp examination revealed severe conjunctival injection with ciliary flush and a large inferior-nasal corneal abrasion with a positive fluorescein eye stain test (Fig. 7). Intraocular pressures were within the normal limits. The anterior chamber was quiescent, and the pupil was round and reactive. Topical moxifloxacin hydrochloride $0.5 \% 3$ times a day and Ozodrop ${ }^{\circledR} 4$ times a day were prescribed. Three days later the patient was without any ocular discomfort and the examination showed a clear cornea, good healing of the defect, and no sign of inflammation (Fig. 8).

\section{Case 2}

A 79-year-old woman presented herself to our department reporting eye pain and irritation, headache, photophobia, and ocular discharge in the right eye. The patient had undergone perforating keratoplasty 10 years previously and in the last 3 months she had been in followup for band keratopathy complicated by an inferior corneal ulcer from the 5 o'clock to the 8 o'clock positions in the same eye. Examination showed perilesional infiltrates and edema, staining at cobalt-blue filtered light (Fig. 9). Intraocular pressures were within the normal limits. The anterior chamber was quiescent, and the pupil was round and reactive. A 7-day regimen of topic Ozodrop ${ }^{\circledR} 4$ times a day was prescribed. Posttreatment evaluation revealed improvement of clinical signs with reduction of the infiltrate and the edema. Moreover, a partial healing of the ulcer with a residual corneal pooling using the cobalt blue filter was shown (Fig. 10). Regarding the related symptoms, only a slight photophobia remained.

\section{Case 3}

A 71-year-old man was referred to our department because of pain and blurry vision in the left eye, which were unresponsive to conventional eye drops. The patient had a history of previous HSV-related corneal ulcer 2 months previously. Correct distance visual acuity was $1 / 20$ with severe photophobia and glare. Examination showed a central, prominent diskshaped area of stromal keratitis (Fig. 11) with a round stromal infiltrate and corneal thinning. Furthermore, a central corneal ulcer positive with staining at cobalt-blue filtered light was highlighted. Intraocular pressures were within the normal limits. The anterior chamber was quiescent, and the pupil was round and reactive. After 10 days of therapy with Ozodrop ${ }^{\circledR} 4$ times a day, corneal involvement was more circumscribed (Fig. 12), signs of staining were 
satisfactorily resolved, and there was significant reduction of photophobia and glare symptoms.

\section{Discussion}

Conjunctivitis in horses represents a therapeutic challenge because it requires different active principles to be administered, almost never present a single eye drop, and the horses tend to get uncooperative in a short time, so the veterinarian often has to resort to alternative methods of treatment (i.e., subpalpebral lavage systems). In this case of recurrent conjunctivitis secondary to retrobulbar lesion, the ozone-based eye drops were effective in solving the problem. The frequency of 3 times daily was well tolerated by the animal that showed good compliance with the treatment and long-lasting therapy results. Conjunctivitis in cats represents a common problem and traditional therapy involves the use of topical antibiotics and NSAIDs, and in some cases even systemic. In this case the ozone-based eye drops were able to reduce the congestion of conjunctiva in 10 days of application. Moreover, after only 3 days of treatment Enterococcus spp. was no longer detected and the total bacteria count had decreased to levels considered normal in cats. Entropion represents a common problem in brachycephalic dogs and the cornea is often affected by entropion-related changes such as erosion/ulceration, inflammation, neovascularization, and pigmentation. Entropion management is usually surgical and requires general anesthesia. In cases such as the present one, where surgery could not be quickly performed, ozone-based eye drops were able to reduce the discomfort of the dog and improve corneal health, despite the persistence of an underlying cause (mechanical clutch of the hairs of the lids on the cornea).

Human microbial keratitis is an ophthalmic public health problem, being one of the leading causes of blindness and visual impairment with significant economic consequences all over the world. Risk factors such as wearing contact lenses, trauma, intraocular surgery, ocular surface disease, and systemic diseases may promote the microorganism adhesion and the infection. In recent years the increasing number of antibiotic-resistant bacteria has motivated prospective research towards the discovery of new antimicrobial strategies. The literature shows that collagen cross-linking (CXL) may be an alternative treatment for refractory cases of human HSV and bacterial keratitis. Reactive oxygen species produced by CXL can eliminate or suppress the proliferation of pathogens through the destruction of the nucleic acids [11]. Recent findings support that CXL could be an acceptable complementary method for the treatment of infectious keratitis [12]. Due to its great oxidative power, the ozone molecule, stabilized for topical use, can be a viable alternative and an easier approach. Our experience seems to confirm the safety and effectiveness of such therapy with no side effects.

This preliminary in vivo study has demonstrated that ozone-based eye drops have an anti-inflammatory and bactericidal activity, in addition to promoting tissue repair. All of these beneficial and therapeutic effects are contained in a unique ocular preparation, reducing the risk of noncooperation of patients in receiving medications. Ozone-based eye drops are very attractive due to their versatility and to various potential uses in ophthalmology.

In conclusion, from our preliminary results, ozone-based eye drops represent a valid and suitable alternative therapy for the management of external ocular pathologies in both animals and humans. Furthermore, given their antimicrobial properties, ozone-based eye drops could be used as an aid for the preparation for intra- and extraocular surgical procedures (i.e., cataract surgery or intravitreal injection). However, more studies are needed to confirm these data. 


\section{Statement of Ethics}

The study was approved by the University's ethics committee.

\section{Disclosure Statement}

The authors have no financial or proprietary interest in the materials presented herein.

\section{References}

1 Elvis AM, Ekta JS. Ozone therapy: A clinical review. J Nat Sci Biol Med. 2011 Jan;2(1):66-70.

2 Kim HS, Noh SU, Han YW, Kim KM, Kang H, Kim HO et al. Therapeutic effects of topical application of ozone on acute cutaneous wound healing. J Korean Med Sci. 2009 Jun;24(3):368-74.

3 Bocci VA, Zanardi I, Travagli V. Ozone acting on human blood yields a hormetic dose-response relationship. Transl Med. 2011 May;9(1):66.

4 Valacchi G, Fortino V, Bocci V. The dual action of ozone on the skin. Br J Dermatol. 2005 Dec;153(6):1096100.

5 Bocci V. Oxygen-ozone therapy: a critical evaluation. Dordrecht: Kluwer Academic Publisher; 2002.

6 Bocci V. Ozone: A new medical drug. Dordrecht: Springer; 2005.

7 Hendrix DV. Diseases and surgery of the canine conjunctiva and nictitating membrane. Hoboken: Blackwell Publishing; 2007.

8 Baeyens V, Felt-Baeyens O, Rougier S, Pheulpin S, Boisramé B, Gurny R. Clinical evaluation of bioadhesive ophthalmic drug inserts (BODI) for the treatment of external ocular infections in dogs. J Control Release. 2002 Dec;85(1-3):163-8.

9 Sechi LA, Lezcano I, Nunez N, Espim M, Duprè I, Pinna A et al. Antibacterial activity of ozonized sunflower oil (Oleozon). J Appl Microbiol. 2001 Feb;90(2):279-84.

10 Bardi JS. News and views. Scripps Research Institute; 2002.

11 Tabibian D, Mazzotta C, Hafezi F. PACK-CXL: corneal cross-linking in infectious keratitis. Eye Vis (Lond). 2016 Apr;3(1):11.

12 Khalili MR, Jahadi HR, Karimi M, Yasemi M. Corneal collagen cross-linking for treatment of bacterial and herpetic keratitis. J Clin Diagn Res. 2017 Jul;11(7):NC12-6. 


\section{Case Reports in Ophthalmology}

\begin{tabular}{l|l}
\hline Case Rep Ophthalmol 2018;9:287-298 \\
\hline DOI: 10.1159/000488846 & $\begin{array}{l}\text { @ } 2018 \text { The Author(s). Published by S. Karger AG, Basel } \\
\text { www.karger.com/cop }\end{array}$ \\
\hline
\end{tabular}

Spadea et al.: Use of Ozone-Based Eye Drops

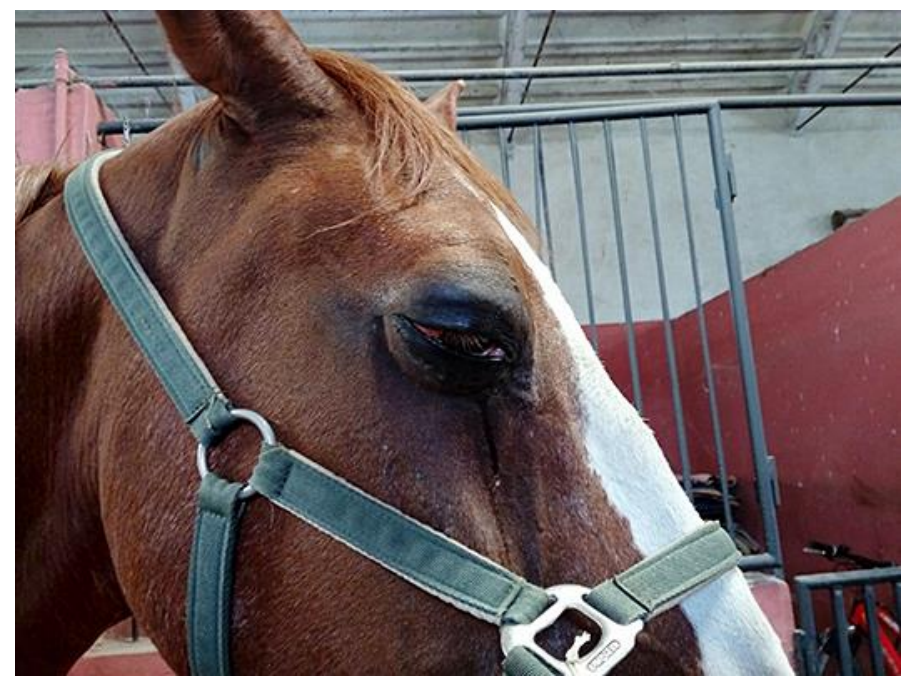

Fig. 1. Right eye of a 26-year-old horse before starting the treatment. Note blepharitis and blepharospasmus, edematous and hyperemic conjunctiva, and plenty of mucous ocular discharge.

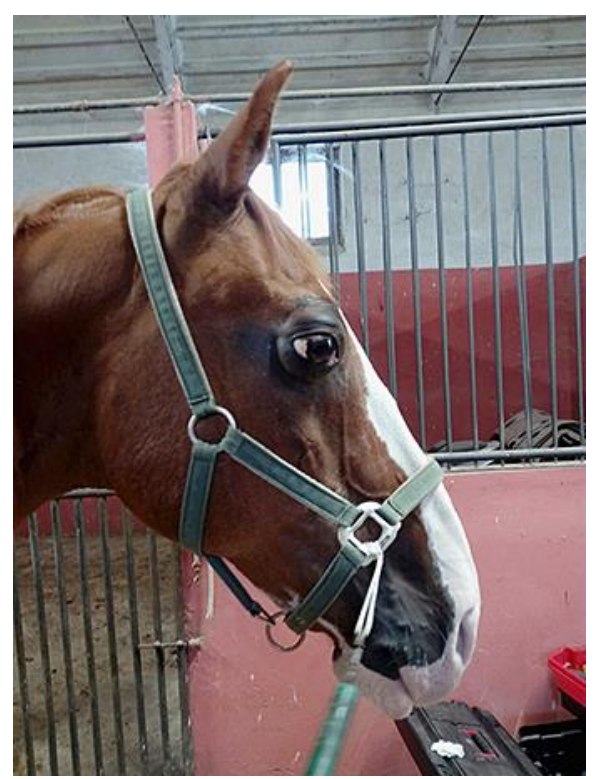

Fig. 2. Same eye of Figure 1 after 7 days of therapy. Normal eye. 


\section{Case Reports in Ophthalmology}

\begin{tabular}{l|l}
\hline Case Rep Ophthalmol 2018;9:287-298 \\
\hline DOI: 10.1159/000488846 & $\begin{array}{l}\text { ○ 2018 The Author(s). Published by S. Karger AG, Basel } \\
\text { www.karger.com/cop }\end{array}$ \\
\hline
\end{tabular}

Spadea et al:: Use of Ozone-Based Eye Drops

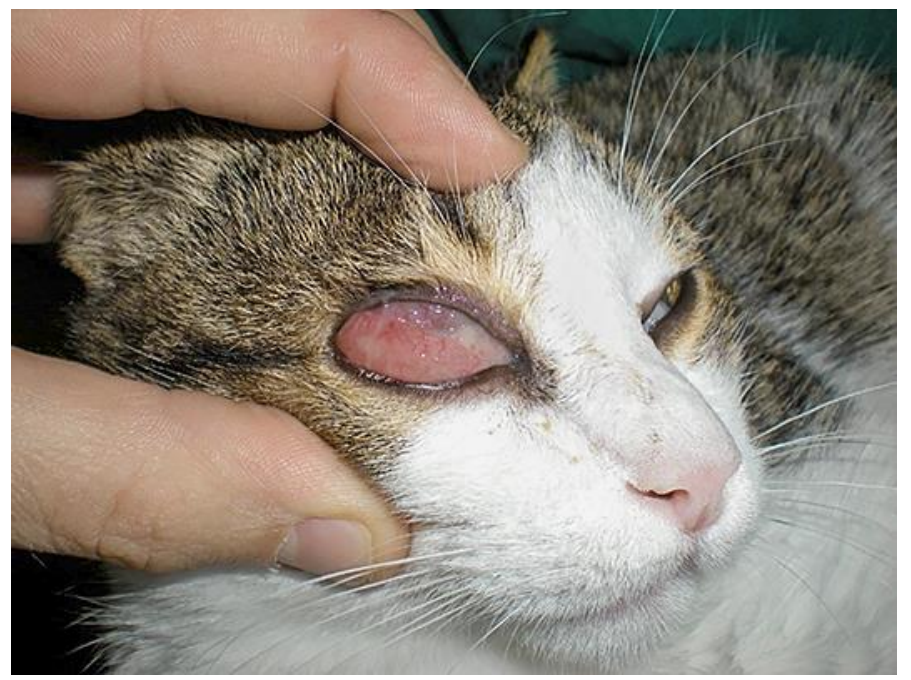

Fig. 3. Right eye of a 6-month-old cat before starting the treatment. Note marked conjunctival edema, reddening of the conjunctiva, and mucous discharge.

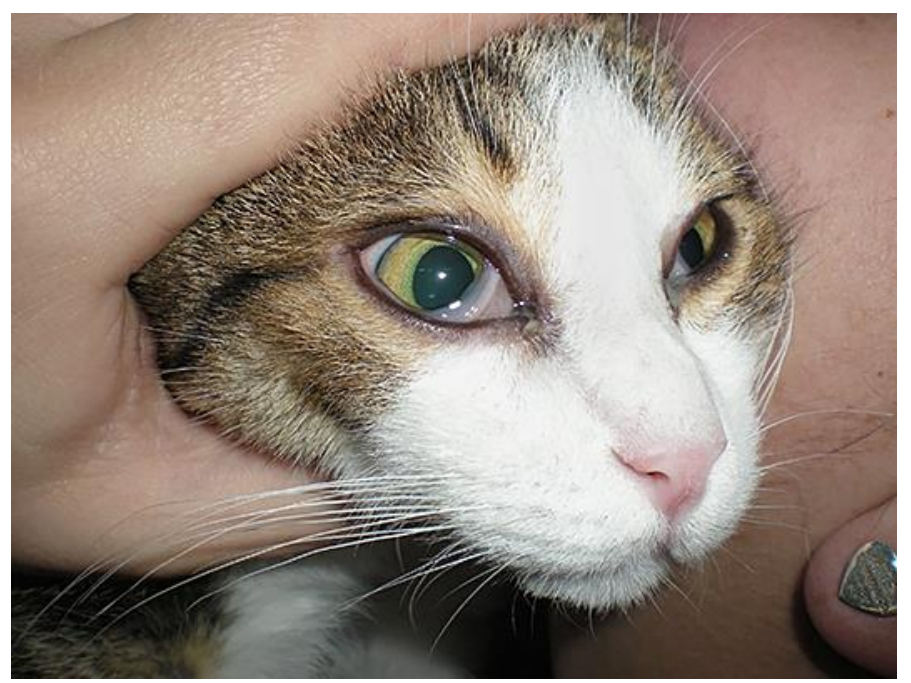

Fig. 4. Same eye of Figure 3 after 10 days of therapy. Normal eye, with mucous discharge still present. 


\section{Case Reports in Ophthalmology}

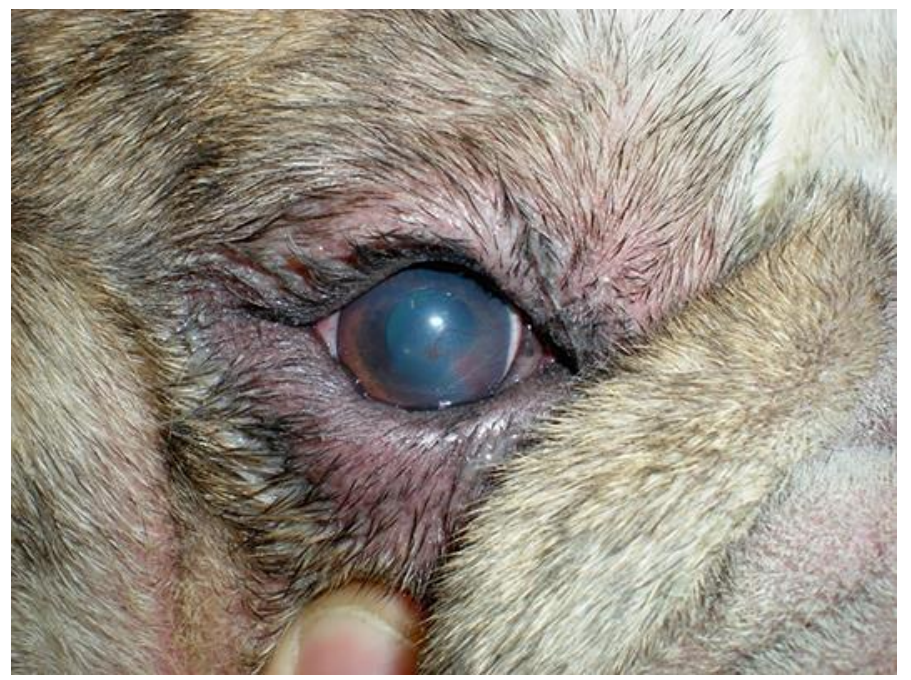

Fig. 5. Right eye of a 3-year-old English bulldog before starting the treatment. Note entropion, mucous discharge, keratitis, corneal edema, and deep and superficial neovascularization.

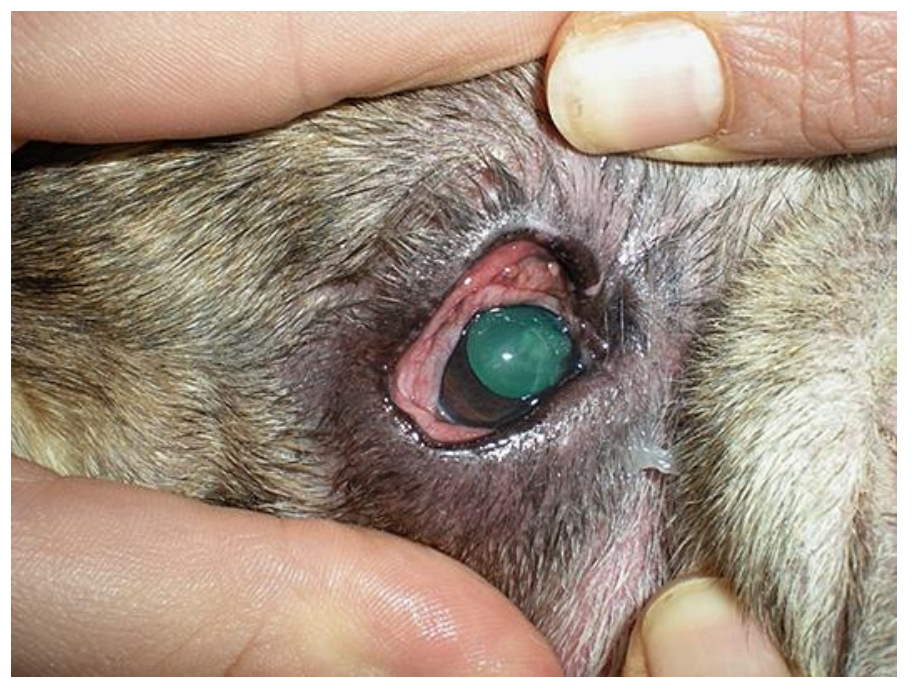

Fig. 6. Same eye of Figure 5 after 10 days of therapy. Corneal edema has resolved and neovascularization remains only with a single, small caliper vessel arising from the limbus at the level of the medial cantus. Entropion and mucous discharge are still present. 


\section{Case Reports in Ophthalmology}

\begin{tabular}{l|l}
\hline Case Rep Ophthalmol 2018;9:287-298 \\
\hline DOI: 10.1159/000488846 & $\begin{array}{l}\text { @ } 2018 \text { The Author(s). Published by S. Karger AG, Basel } \\
\text { www.karger.com/cop }\end{array}$ \\
\hline
\end{tabular}

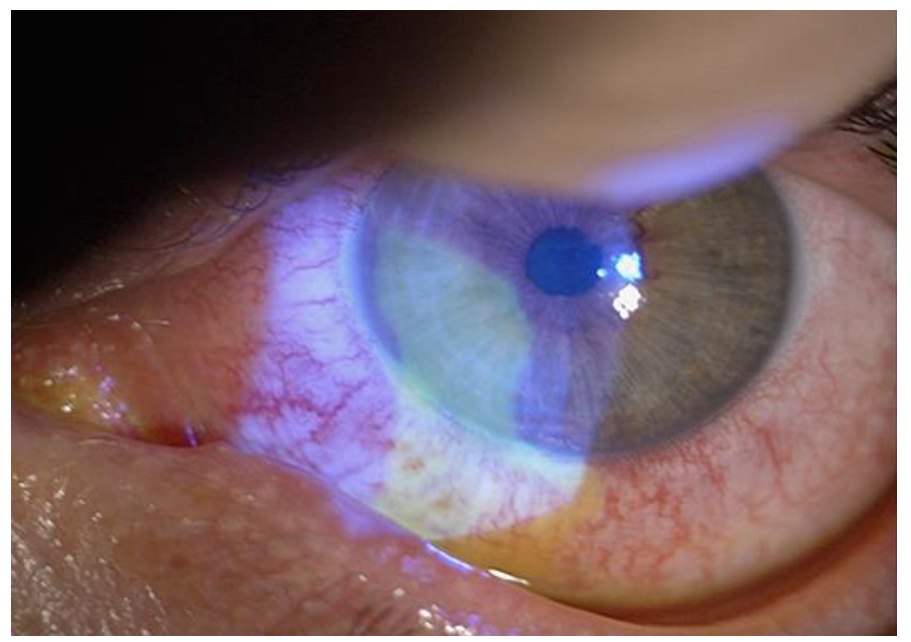

Fig. 7. Left eye of a 33-year-old man before starting the treatment. Note ciliary flush and large epithelial defect.

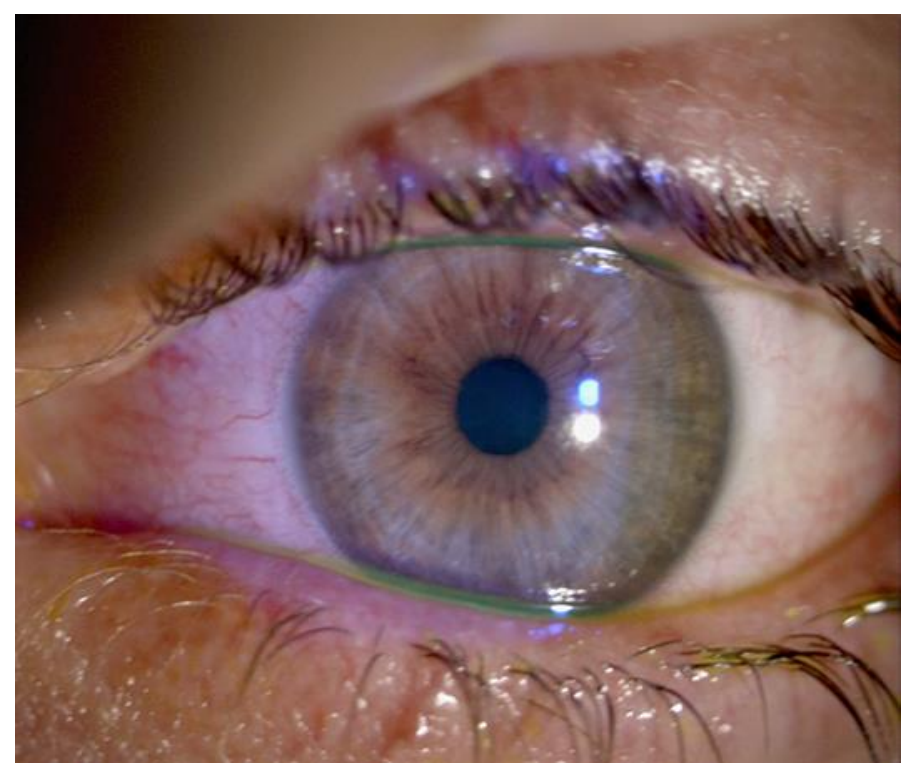

Fig. 8. Same eye of Figure 7 after 3 days of therapy; the appearance is normal epithelium with no inflammatory signs. 


\section{Case Reports in Ophthalmology}

\begin{tabular}{l|l}
\hline Case Rep Ophthalmol 2018:9:287-298 \\
\hline DOI: 10.1159/000488846 & $\begin{array}{l}\text { ( ) 2018 The Author(s). Published by S. Karger AG, Basel } \\
\text { www.karger.com/cop }\end{array}$ \\
\hline
\end{tabular}

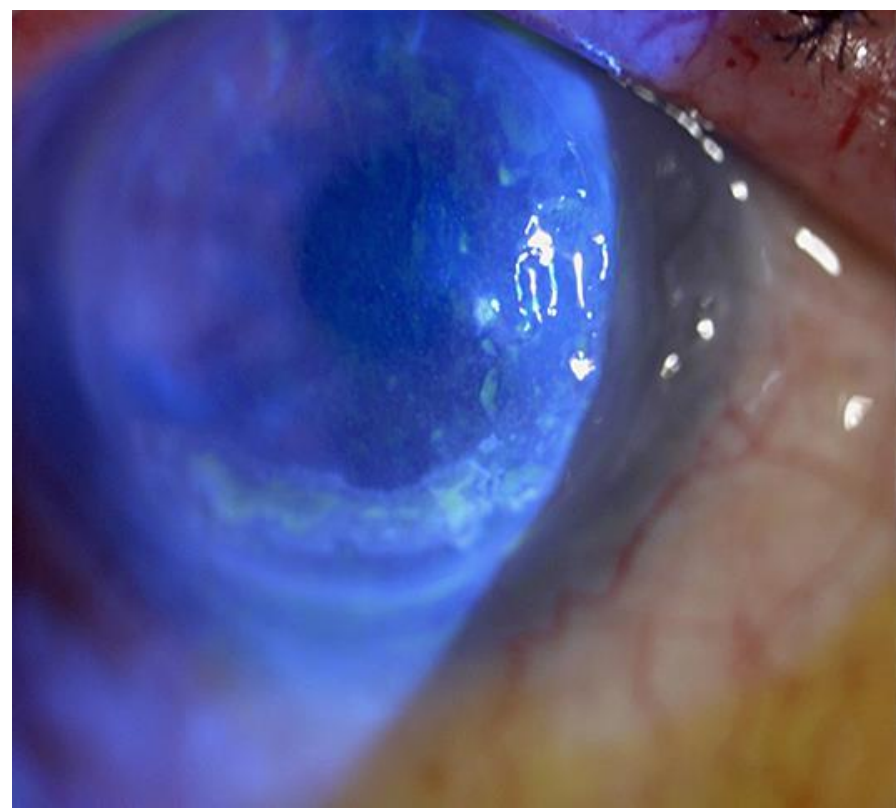

Fig. 9. Right eye of a 79-year-old woman before starting the treatment. Note inferior corneal ulcer from the 5 o'clock to the 8 o'clock positions.

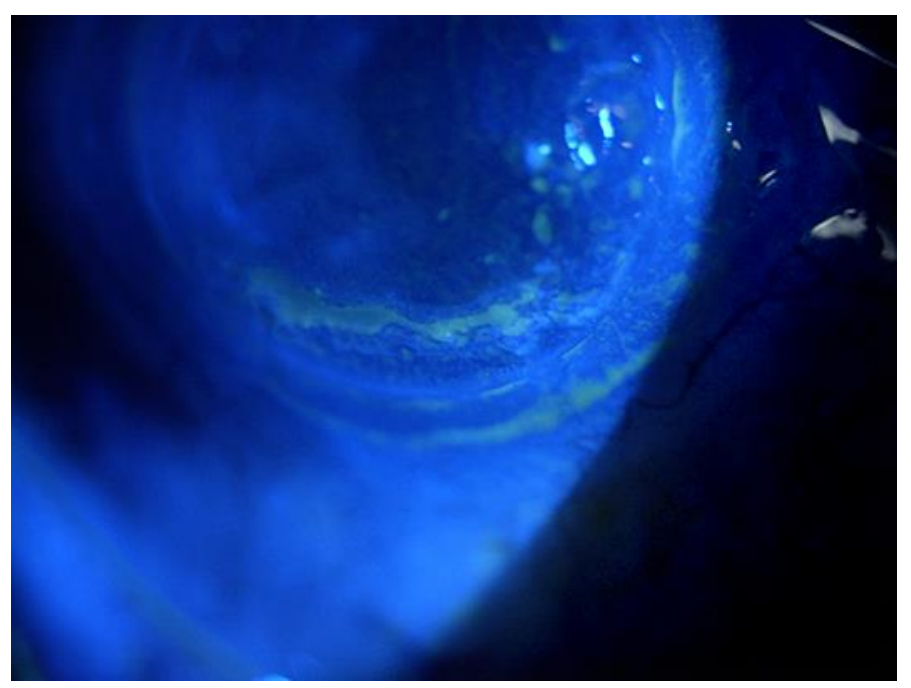

Fig. 10. Same eye of Figure 9 after 7 days of therapy. Partial healing of the ulcer with a residual corneal pooling. 


\section{Case Reports in Ophthalmology}

\begin{tabular}{l|l}
\hline Case Rep Ophthalmol 2018;9:287-298 \\
\hline DOI: 10.1159/000488846 & $\begin{array}{l}\text { @ } 2018 \text { The Author(s). Published by S. Karger AG, Basel } \\
\text { www.karger.com/cop }\end{array}$ \\
\hline
\end{tabular}

Spadea et al:: Use of Ozone-Based Eye Drops

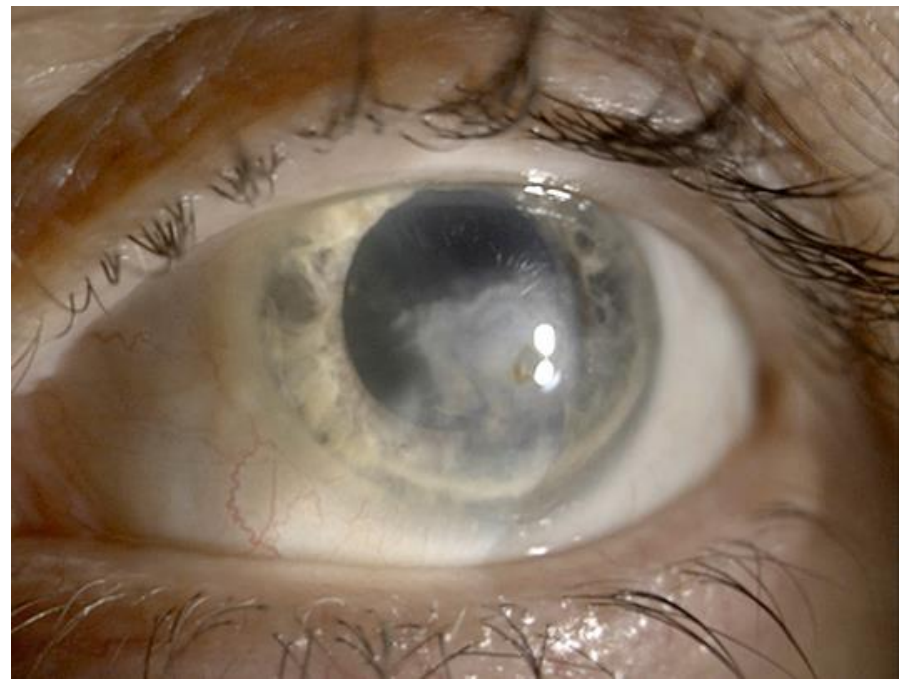

Fig. 11. Left eye of a 71-year-old man before starting the treatment. Note stromal keratitis and corneal ulcer.

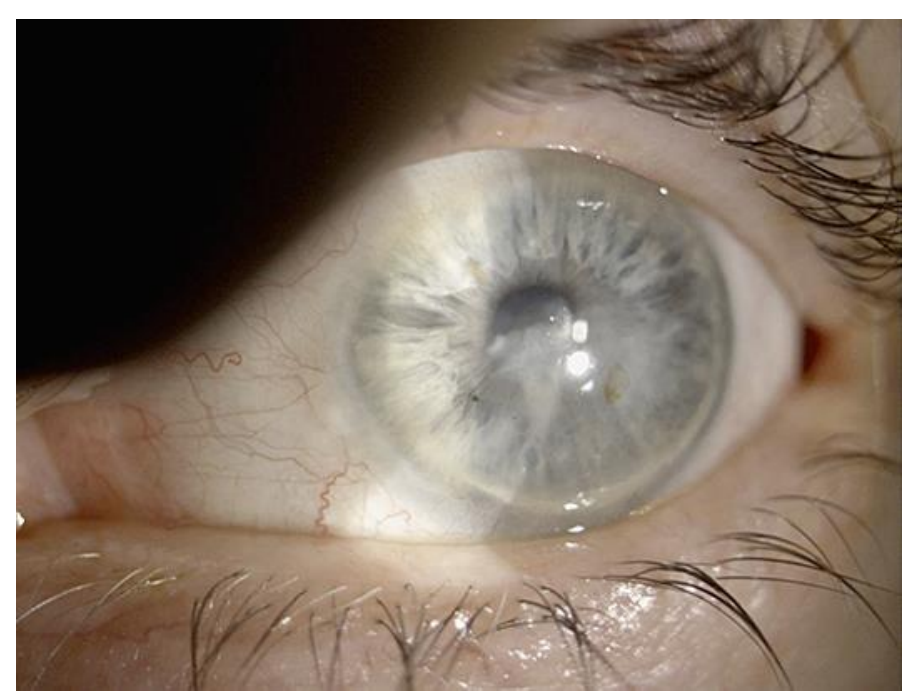

Fig. 12. Same eye of Figure 11 after 10 days of therapy. Resolution of corneal ulcer with negative staining. 